Esta conferencia hace parte de la investigación Edición crítico-genética y estudio previo de la obra poética (1940-2006) de Héctor Rojas Herazo, desarrollada en el marco del Doctorado en Literatura de la Universidad de Antioquia, y sustentada el 30 de noviembre de 2021 en Medellín, cuyo informe final recibió la distinción Summa cum laude.

Cómo citar esta conferencia: Santos García, E. (2022). Lámparas en la niebla, de Héctor Rojas Herazo: problemas pre-textuales y textuales de un poemario póstumo. Estudios de Literatura Colombiana 50, pp. 167-178. DOI: https://doi.org/10.17533/udea.elc. $\underline{\mathrm{n} 50 \mathrm{a} 09}$

${ }^{1}$ https://orcid.org/0000-0003-0545-0150 emirosantosgarcia@gmail.com Universidad de Cartagena, Colombia

Editores: Andrés Vergara Aguirre, Christian Benavides Martínez

Recibido: 10.12 .2021

Aprobado: 14.12.2021

Publicado: 17.01 .2022

Copyright: (92022 Estudios de Literatura Colombiana. Este es un artículo de acceso abierto distribuido bajo los términos de la Licencia Creative Commons AtribuciónNo comercial - Compartir igual 4.0 Internacional

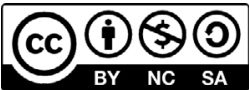

\section{LÁMPARAS EN LA NIEBLA, DE HÉCTOR Rojas Herazo: problemas PRE- TEXTUALES Y TEXTUALES DE UN POEMARIO PÓSTUMO*}

\author{
LÁMPARAS EN LA NIEBLA, BY HÉctor RoJAs \\ Herazo: Pre-textual and Textual \\ Problems of a Posthumous Collection \\ of Poems
}

Emiro Santos García ${ }^{1}$

En el mes de agosto de 2021 tuve la oportunidad de finalizar un proceso de escritura de más de cuatro años, que venía gestándose desde el 2011, cuando publiqué Héctor Rojas Herazo: el esplendor de la rebeldía, libro que trataba sobre las representaciones del cuerpo en la estética del poeta colombiano. El nuevo proceso correspondió a un trabajo más arduo, pero no menos satisfactorio: la fijación textual y el establecimiento crítico-genético de la poesía completa de Héctor Rojas Herazo, que incluyó tanto la producción dispersa en periódicos y revistas regionales como la publicada en formato de libro entre 1940 y 2006. Un estudio que abarcó más de seis décadas de oficio de uno de los grandes renovadores de la poesía colombiana. Nacido en Santiago de Tolú, en 1920, Héctor Rojas Herazo falleció en Bogotá, a los 82 años, poco antes de que se publicara la compilación de su obra poética por el Instituto Caro y Cuervo, y cuatro años antes de la aparición de su último trabajo lírico. 
A propósito del 2021 — declarado por el Ministerio de Cultura de Colombia como el Año Héctor Rojas Herazo, en conmemoración del centenario del nacimiento del escritor y pintor sucreño-, quiero referirme a las particularidades y problemas genéticos de uno de los poemarios menos estudiados pero más intrincados de Héctor Rojas Herazo, a pesar de su extensión: la colección póstuma Candiles en la niebla. Publicado en el 2006 por la Universidad del Norte y la Gobernación del Atlántico, su edición fue resultado de la compra de los manuscritos y mecanuscritos del poeta a Patricia Rojas Barboza y Alfonso Rojas Barboza, hijos de Héctor Rojas Herazo, por parte de la Universidad del Norte. Un ya anciano poeta había entregado a su hija en marzo del 2002, un mes antes de morir, un grupo de pre-textos manuscritos. Un legajo que fue dado más tarde a la prensa con un título poco común para el usus scribendi del autor: Candiles en la niebla. Este poemario implicará desde entonces toda una excepción, ya que corresponde al único del autor que permite acceder a sus estratos escriturales, con un material pre-textual plenamente identificable, que no fue destruido o que no se perdió durante el proceso editorial, como ya había ocurrido antes con los pre-textos de las editio princeps de Rostro en la soledad (1952), Tránsito de Cain (1953), Desde la luz preguntan por nosotros (1956), Agresión de las formas contra el ángel (1961), o incluso uno más reciente: Las úlceras de Adán (1995).

Así, pues, nos encontramos ante un producto estético en el que convergen todas las etapas creativas del autor: la etapa formativa, que va de 1940 a 1951, en Cartagena, Barranquilla y Bogotá; la etapa de madurez, que comprende la primera parte de su estadía en Bogotá, entre 1952 y 1961; y la etapa de balance, realizada, en términos editoriales, entre 1995 y 2006, después del regreso de España y que culmina tras su muerte (Santos García, 2021a y 2021b). El poemario presenta una serie de posibilidades de interpretación genética bastante excepcionales, pero también las dificultades de "fijación" textual más serias de su obra lírica. Variadas son las características del libro, que implica cuatro grandes órdenes de variación genética: a) uno textual, relativo a la titulación del poemario; b) uno pre-textual, correspondiente a la datación de los poemas; c) uno co-textual, que corresponde a la organización interna del poemario; d) y uno editorial, concerniente a las decisiones ecdóticas implementadas para el paso de los pre-textos manuscritos y mecanuscritos al formato de libro.

En el caso de la primera dificultad, encontramos inestabilidades morfológicas y semánticas para el título. Después de indagar en la prensa cartagenera de los años 
40, en la Biblioteca Bartolomé Calvo del Banco de la República pude encontrar una nota del 18 de septiembre de 1948, publicada en el diario El Universal, que menciona un temprano proyecto poético cuyo título sería Lámparas en la niebla. De la nota puede deducirse que el poemario venía gestándose en los últimos meses o incluso en el último año. Esta nota, además, acompañaba la publicación de un texto de juventud — “Poema de la profunda despedida”, escrito en 1938, cuando Héctor Rojas Herazo todavía era un adolescente-, y puede atribuirse al periodista Clemente Manuel Zabala, encargado de la sección "Antología" de El Universal. No es descartable, sin embargo, la intervención de Héctor Rojas Herazo, puesto que la nota evidencia en algunos momentos afinidades vocabulares (o lo que también puede indicar que el uso vocabular del joven poeta está permeado por la prosa de Zabala):

En plena adolescencia inicia Héctor Rojas Herazo la publicación de sus poemas, en Barranquilla, hacia 1939. Desde sus primeros logros relieva una ley lírica poderosa y jubilar. Fuerza meditativa. Lumbre elegiaca. Corazón poético de limpio latido. Sigue labrando sus instrumentos por dispares y, a veces, flagelados caminos. Su obra, dispersa en varias ciudades del país, es una de las más sinceras constancias de la reciente lírica colombiana. Todos sus críticos apuntan a su fuerza. Quisiéramos, más bien, destacar su manera de doblegarla al misterio. Su ademán de potencia que impone una gracia. Su plástica de ávido torso en busca de ojos propios donde situar la respiración. Ascética pura de lo absoluto, pura y extremada, esta poesía nace, muchas veces, ante la presencia dolorosa de los presagios divinos, ante ese inmenso ser que se integra en la fuga de los seres. Atenta siempre al mundo como signo de una Voluntad Superior, busca aquel idioma perdido para nosotros y restaurado milagrosamente en una simple rosa olvidada de todos los seres. Tiene en preparación "Lámparas en la Niebla" (poemas) (El Universal, 1948, p. 7).

La temprana referencia al título "Lámparas en la niebla" habla de un proyecto que coincide con el camino hacia la madurez del autor, quien ha publicado hace poco los más logrados poemas de su etapa formativa en El Heraldo del 30 de diciembre de 1947, pero no todavía el poema "Jaculatoria a los seres creados" de octubre-noviembre de 1948, en Revista de América (Bogotá); ni los más maduros del 1 de octubre de 1949, en Sábado (Bogotá). Si bien es cierto que Héctor Rojas Herazo no da a la imprenta en los próximos años un poemario con el título Lámparas en la niebla - no encontramos tampoco nuevas menciones en la prensa regional o nacional, lo que puede llevarnos a concluir que el poemario corresponde al futuro Rostro en la soledad (1952) - , la presencia de un vocablo como "lámpara" marca importantes recurrencias en la titulación de varias de sus notas de prensa de juventud: "La lámpara de Eduardo Castillo" (El Universal, 22 de junio de 1950), "El hermano entre las lámparas”(Diario de Colombia, 12 de diciembre de 1952) y "Breve inventario de techumbres y lámparas" 
(Diario de Colombia, 9 de junio de 1955). O también en los versos de los poemas más notables de Rostro en la soledad, su opera prima: "La casa entre los robles", "El encuentro", "E1 habitante destruido", “Agonía del soldado", "Viento del huésped” y "Elegía”.

Una nueva y tardía mención del título volverá a ocurrir solo en marzo de 2002 — cincuenta y cuatro años después de la nota de 1948-, cuando Beatriz Peña Dix (2004) indique en su estudio preliminar a la obra poética de Rojas Herazo que uno de los "planes inmediatos" del autor — además de la preparación de una exposición de pintura - consiste en "culminar Lámparas en la niebla, su próximo trabajo de poesía, que, en realidad, ha estado en construcción por casi cincuenta años [...]” (p. 30). La fecha del estudio preliminar de Peña Dix corresponde a marzo de 2002 y la versión final aparece publicada en el 2004 - los estudios de la obra poética "se elaboraron con la ayuda y revisión final del maestro [...], pocos meses antes de su fallecimiento” (p. 30)Así, pues, si tenemos en cuenta que el poeta fallece el 11 de abril del 2002, la voluntad de titulación de Candiles en la niebla como Lámparas en la niebla alcanza el umbral mismo de su última trayectoria vital y estética.

¿Qué ocurre con el título tras la muerte del autor? ¿Corresponden los manuscritos de Lámparas en la niebla y el texto impreso de Candiles en la niebla al proyecto iniciado en 1948 en Cartagena? ¿O su título solo comporta una remanencia nominal? El nombre Lámparas en la niebla no vuelve a aparecer después del mes de marzo de 2002. El 12 de abril el diario El Tiempo informa que el "pintor y escritor Héctor Rojas Herazo falleció ayer, a las 5 p. m., en Bogotá, víctima de un ataque cardiaco. El autor de novelas como En noviembre llega el arzobispo y Celia se pudre trabajaba en un nuevo libro de poemas que llevaría el título de Lámpara en la oscuridad, informó su hija $\mathrm{Pa}$ tricia" (Archivo Biblioteca Nacional de Colombia [ABNC]: MP1-2533, fol. 74). El 15 de abril leemos de nuevo en El Tiempo: "Pintor, poeta y novelista dueño de una de las prosas más ricas y expresivas, Héctor Rojas Herazo se cansó de esperar que llegara el arzobispo de su famosa novela En noviembre llega el arzobispo, y decidió abandonarnos el pasado viernes, a sus 81 años. Un infarto le impidió terminar su nuevo libro de poemas, Lámparas en la oscuridad" (ABNC: MP1-2533, fol. 83). Ya que las notas de prensa están expuestas a urgencias y descuidos de transcripción —una de estas notas informa, por ejemplo, que el fallecimiento ocurrió en Cartagena y no en Bogotá (ABNC: 21 de abril de 2002, MP1-2533, fol. 77)—, no siempre constituyen una fuente fiable para la valoración de variantes. ¿Cómo enfrentarse entonces al cambio de título 
entre marzo y abril, y luego al reemplazo definitivo de "lámparas" por "candiles" en 2006? Acerca de la importancia del vocablo "lámpara" para la trayectoria biográfica e intelectual de Héctor Rojas Herazo, evoca Patricia Rojas Barboza:

[...] Él le decía a mi madre que era una persona-lámpara, porque donde se sentaba iluminaba el sitio. La luz para mi padre era primordial y asoció siempre la lámpara con el encendimiento terrestre. Para él, la luz, tanto del sol como de las lámparas que iluminan la noche, nos hacen creer que estamos solarmente atendidos. Las lámparas le fascinaban. Decía de los bares de España: "parecen lámparas". Y, claro, los bares de España, cuando anochece, son como lámparas encendidas (entrevista a Patricia Rojas Barboza, 22 de abril de 202I).

El vocablo “candil” — tan ajeno al vocabulario poético de Héctor Rojas Herazo (su lenguaje lírico se encuentra obsedido por la mitologización léxica) — no aparece en las columnas de prensa que hemos consultado de su obra periodística ni tampoco en sus poemas. ¿Qué lugar ocupa en el marco de las lógicas revisionistas del autor, quien ya había modificado en los años 50 títulos como Arribo terrestre por Rostro en la soledad, y en los 90, Infidencia terrestre por Las úlceras de Adán? Y todo esto siempre sin abandonar las implicaciones mito-poéticas de su simbolismo léxico muy personal. Puedo conjeturar en este punto dos caminos genéticos: a) una variante autoral incorporada en el muy breve periodo que va de marzo a abril del 2002; es decir, menos de un mes antes de su fallecimiento; y b) una intervención editorial póstuma, comprendida entre 2002 y 2006, como parte del proceso de preparación de los materiales pre-textuales para su publicación en formato de libro.

En alguno de los dos casos el cambio pudo obedecer a un criterio externo: "Jorge García Usta había ya utilizado Vigilia de las lámparas para la compilación de la serie periodística” (entrevista a Patricia Rojas Barboza, 2021), que sería publicada un año después de la muerte del autor. Acerca de la posibilidad de una intervención editorial póstuma, la compilación de Jorge García Usta pudo influir en los criterios de titulación del poemario, puesto que sus editores habrían procurado evitar coincidencias que restaran singularidad al libro. En cualquiera de los casos, estas particularidades genéticas y textuales nos piden volver críticamente a la voluntad sostenida por Héctor Rojas Herazo a lo largo de cinco décadas; a la coherencia de su estética (no solo en el ámbito estilístico, sino simbólico); y a la depuración de las motivaciones contextuales, que pudieron afectar la autonomía del texto bajo un ámbito que excede lo poético. A casi dos décadas de publicada la compilación de Jorge García Usta, una nueva edición de Candiles en la niebla con la restauración del título Lámparas en la 
niebla puede devolver, sin condicionamientos extraliterarios, la primacía de una voluntad estética. No debe olvidarse aquí tampoco que la culminación de Candiles en la niebla está marcada por el deterioro físico y por el intenso duelo del poeta, quien en agosto de 2001 perdió a su principal soporte emocional, Rosa Isabel Barboza, "la niña Rochi”, su esposa por más de cinco décadas. El doloroso acontecimiento lo sumió en una profunda postración e hizo del "cierre" de Candiles en la niebla el proceso creativo más difícil de todos los experimentados por el autor. Relata Patricia Rojas Barboza:

Mi mamá muere en agosto y mi padre solo vuelve a escribir a los tres meses, después de llorar muchísimo, porque permanecía muy mal. Empieza a escribir a los tres meses; pero él ya tenía varios poemas. Empieza a escribir en noviembre del 2001 y termina en enero o febrero del 2002. "Ya esto está", me dijo. "Ya no tengo más nada que escribir. Esto ya lo puedes guardar". Yo entonces lo recopilé y pasamos los manuscritos a máquina. Todo quedó pulido. Mi papá termina el poemario más o menos en febrero. Marzo le quedó libre y en abril murió (Rojas Barboza, 202I).

Si tenemos en cuenta que la finalización de Candiles en la niebla ocurre entre febrero y marzo de 2002 - lo que coincide de cerca con los datos suministrados por Beatriz Peña Dix - la versión final de los poemas corresponde al producto de un hombre de más de ochenta años, con la salud intacta, pero llevado al límite por la pérdida. Así lo describe su hija:

Mi papá tuvo una especie de purgatorio. Como ella se fue [Rosa Isabel Barboza], puede que empezara a pensar en qué no había hecho bien, en qué había hecho mal. iTantas cosas! Era como si se estuviese purificando para morir, para poder morir en paz. Porque mi madre lo acompañó mucho. Él era muy difícil como persona, pero él siempre quiso ser bueno, y eso hay que reconocérselo. Mi mamá lo sabía. Le aguantaba su genio. Pero al final logró una paz que no tuvo en los años violentos de Respirando el verano o de sus primeros cuatro poemarios (Rojas Barboza, 2021).

Durante la última etapa de trayectoria estética, las modulaciones del "purgatorio" de su voz lírica apelan a la condensación de textos que se han despojado de todo barroquismo y desmesura verbal, y desarrollan un inventario de los conflictos mito-poéticos definitorios de lo que fue su poesía de madurez. No es extraño que encontremos poemas con registros bélicos afines a los publicados en 1961 (Agresión de las formas contra el ángel), o a los conciliatorios de los 90 (Las úlceras de Adán), e incluso de interrumpido cuño, como el grupo de poemas destinados al proyecto inconcluso Mascando las tinieblas en el odio (c. 1959-1960). El primer estrato escritural —el más antiguo - recoge cinco poemas de 1959 y 1960, procedentes del proyecto Mascando las tinieblas en el odio, que fueron incluidos de manera póstuma. Estos son: 
"Cataclismo para merecer la aurora" (1959), "El ruido que nos llama entre nosotros" (1960), “Los desplazados” (1960), “Redoble de lástimas” (1960) y “Lamentación del campesino emasculado" (1960). Una serie de poemas con pre-textos mecanuscritos y correcciones autógrafas que abordan los estragos de la Violencia colombiana, tema que Héctor Rojas Herazo solo exploró de manera directa a finales de los 50 - "Palabras elegiacas a un soldado" de 1947 parece referirse más a la Guerra Civil—, pero que forjan parentesco con su corpus poético de madurez debido a la reescritura del mito del destierro del Paraíso. En este caso, el desplazamiento forzoso del campo a la urbe. Si bien estos cinco poemas de violencia están fechados, no son los únicos que pudieron haber hecho parte de un libro como Mascando las tinieblas en el odio, ya que sus ramificaciones estilísticas y temáticas alcanzan otros poemas posteriores, sin fecha, como "Puntos en el aire", "Los camaradas desfilan otra vez en la memoria", "Masticando la tristeza en el olvido" y "Memoria ulcerada”. Acerca del libro de poemas abandonado, explica Patricia Rojas Barboza:

Mascando las tinieblas en el odio es un libro que él quería hacer sobre la bandera, sobre los obituarios, sobre los hombres trabajando en las alturas - mi padre le tenía terror a las alturas y cuando los veía allá arriba le daba escalofrío-. Hay muchas cosas que él escribió sobre eso. Era un libro que se basaba en la vida misma, en el transcurrir, en los obituarios. Pero para entonces ya tenía una gran desilusión con los libros de poemas, con su poesía. Los únicos que sacaban sus libros de poesía eran la Editorial Kelly; y Camilo Restrepo, director de la revista Cromos, un gran amigo suyo, le brindaba ayuda. Mi papá veía que era un sufrimiento hacer un libro, porque no lo editaban. Era muy difícil editarlo, a menos que intervinieran los amigos. Mi papá se desilusionó muchísimo. Tanto así que duró más de treinta años en sacar su siguiente poemario (Rojas Barboza, 202I).

El segundo grupo y estrato escritural de Candiles en la niebla comprende siete poemas de datación intermedia, agrupados bajo el título "Obituarios", cuyo origen puede seguirse hasta la estadía de Héctor Rojas Herazo en Madrid, en especial entre 1978 y 1985, e incluso hasta la década de los 60, si se asume que algunos de ellos pudieron hacer parte como idea de Mascando las tinieblas en el odio; pero esto no ha podido ser comprobado hasta ahora. Los "obituarios" recorren la línea temporal que llega hasta muy poco antes de la muerte del autor:

Él los dejaba y los tomaba. Los cogía y los dejaba. No fue algo que le salió totalmente. Ya los termina aquí, en Bogotá, con 8i años, unos meses antes de morir. Recuerdo que él me decía cuando leía los obituarios del periódico: "Mira esto. Mira a este señor que hizo tantas cosas en su vida. Tuvo esperanza. Tuvo fe. Y todo queda ahí, en un obituario. Eso es terrible”. Como al final mi papá ya sabía que se acercaba la muerte, puede que estos poemas le salieran como tenían que haber salido; no antes, porque estaba vital. Él los termina bajo un presentimiento (Rojas Barboza, 202I). 
En este sentido, como concepto — no como materialización verbal—, los seis “obituarios" pudieron muy bien haber hecho parte de una de las tres posibles líneas temáticas originadas en Mascando las tinieblas en el odio, que a su vez continúa las exploraciones sobre el ciudadano común y corriente de poemas como "Responso por la muerte de un burócrata", incluido en Agresión de las formas contra el ángel. Las otras dos líneas pudieron haberse centrado en la expulsión violenta del campo o en la entrada desamparada del campesino en la urbe. Pero lo más interesante de esto radica en que los "obituarios" anticipan y corren paralelos al carácter "mínimo" del tercer y último estrato escritural de Candiles en la niebla, integrado por veintiséis poemas en los que prevalece la contención del verso, la condensación de la imagen poética y la brevedad compositiva. Poemas como "Instante”, "Bruma”, "Nuevo Satán”, "Jeroglífico del fuego" o "Las formas del silencio" implican un vuelco de la estética de Héctor Rojas Herazo. El desbordamiento da paso a la contención. Este último grupo de poemas resulta ser el más amplio y novedoso, y hay pocas dudas de que no concierna al núcleo propiamente dicho de Lámparas en la niebla; pero su datación es la más compleja de todas. Por su estilo y temática, y por las correspondencias intratextuales, los poemas que integrarían este núcleo original pueden ordenarse en un antes y un después de la muerte de Rosa Isabel Barboza, la "niña Rochi”, ya que los pre-textos manuscritos anteriores evidencian estadios redaccionales más cerrados, "finales", y una caligrafía enérgica, vibrante, todavía no deteriorada.

Si desarrollamos un diagrama de la articulación entre lo histórico y lo estético, entre lo biográfico y lo estilístico, podremos ver que los poemas de Candiles en la niebla, editados por la Universidad del Norte y la Gobernación de Bolívar, se encuentran ubicados en el periodo abierto entre el tercer y cuarto poemario - Desde la luz preguntan por nosotros (1956) y Agresión de las formas contra el ángel (1961) _, y antes y después de Las úlceras de Adán (1995). En otras palabras, al final de la etapa de madurez y en el marco del desarrollo pleno de la etapa de balance. Pero en lo que corresponde al proyecto manuscrito del autor, la materialización de una "clausura" de Lámparas en la niebla culmina con un grupo de pre-textos sin orden o índice, que contrasta con las cuidadosas arquitecturas de las colecciones previas en las que la estructura "externa" del poemario es tan importante como la "interna" del poema. Como albacea y protectora del legado paterno, en ausencia de indicaciones más precisas, Patricia Rojas Barboza se encargará de mecanografiar varios poemas (algunos 
de ellos en vida de su padre) y tomará decisiones editoriales para la transmisión del poemario. Este papel protector ya lo venía desempeñando desde la década de los 60:

Aunque no recuerdo el proceso de escritura de un libro como Rostro en la soledad - yo era demasiado pequeña: nací en I95I y el poemario es de 1952-, sí te puedo hablar a partir de los diez años. Él me pedía que le pusiera las hojas de papel carbón en la máquina de escribir. Yo las arreglaba y él me decía: "Así no. Tienes que hacerlo así. Cada vez que te lo pida, tú me las pasas". Esto ocurrió con su primera novela, Respirando el verano, con su cuarto poemario, Agresión de las formas contra el ángel, y con todas las cosas que vinieron después. Mi papá me comentaba cosas y me decía: "Fíjate bien si no hay una palabra repetida...". Así que me tocó estar muy de cerca desde niña [...]. Cuando era un poemario, me avisaba: "Estoy haciendo un libro de poemas"; o si estaba escribiendo para el Magazin Dominical... Porque, entre otras cosas, yo tenía que estar muy pendiente de la corrección de estilo. No de su prosa, la prosa de él era maravillosa, pero el gazapo siempre se mete, y de pronto podía tener una palabra repetida. "iTú escribe!", le decía yo, "No te preocupes" - porque se preocupaba mucho por el gazapo-. “Tú escribe y ya después pulimos”. Efectivamente, así pasaba. Él me avisaba lo que estaba haciendo, porque teníamos que revisarlo entre los dos. En cuanto a los cambios mayores de los poemas, era sumamente personalísimo. Me comentaba muchas cosas, pero sobre las decisiones creativas, no [...]. Yo fui su secretaria, prácticamente. Mi mamá también lo fue mientras yo era una niña. Las dos lo ayudábamos muchísimo, pero después él se apoyó mucho más en mí porque yo estaba más pendiente... Cuando lo de los "Obituarios" -que están en Candiles en la niebla-, él los iba a romper... "No me rompas eso", le dije. "No me rompas eso". Y yo los guardaba. Mi papá siempre se apoyó en mí porque fui su secretaria durante más de cuarenta años (Rojas Barboza, 202I).

Así, muchas de las particularidades genéticas de Candiles en la niebla contribuyen a entender que su inestabilidad es constitutiva del proceso mismo de su imposible "clausura", lo que requiere un tratamiento muy distinto del idicium crítico (o juicio crítico del editor) al que puede implementarse sobre los poemarios publicados en vida del autor $y$, por lo tanto, revisados al menos en dos oportunidades. Candiles en la niebla no solo no cuenta con una segunda edición, sino que la lectura de sus poemas debe atender con mayor énfasis a los vínculos entre contexto/cotexto genético, y a la superposición entre variantes genéticas y variantes editoriales. Por un lado, el autor no alcanza a supervisar la transcripción completa (el paso del manuscrito autógrafo al mecanografiado que sirve de modelo a la editio princeps, como es característico de su labor creativa), ya que esencialmente es un libro inconcluso. Por otra parte, Héctor Rojas Herazo no entrega a sus editores indicaciones numéricas o de otra índole para la ubicación de los poemas.

De ahí que no pueda hablarse, en estricto sentido, de una posibilidad de "fijación" textual de los poemas. El poemario no solo no alcanza a realizarse como totalidad "clausurada", sino que tampoco cuenta con una segunda edición que posibilite un estudio comparativo de testimonios textuales para la construcción de una edición crítica. Las decodificaciones editoriales de las intenciones del autor, a partir del desciframiento y trascripción de la grafía; el análisis de los estadios redaccionales, que 
coexisten o son interrumpidos; la identificación del estadio redaccional más cercano a una etapa de "cierre"; la enmienda ortográfica y la verificación del usus scribendi de cada poema; así como la depuración de las intervenciones de los distintos editores (ya sea al momento de la primera transcripción o de la publicación de la editio princeps), demandan un aparato crítico-genético que presente al lector los movimientos redaccionales y editoriales, y pueda estabilizar los más cercanos a la voluntad última u ofrecer una comprensión diacrónica de los que abren y no cierran caminos estéticos.

En este sentido, clasifiqué los poemas con los que trabajé en el 2020 y el 2021 en tres grupos: a) poemas "clausurados", con testimonios pre-textuales autógrafos (como son los casos de "Otro delirio en el secreto", "Las formas del silencio" y "Jeroglífico del fuego); b) poemas con testimonios pre-textuales mecanuscritos (como "Instante", "Las mieles de la noche", "E1 forastero" o "Cortejo de reyes para un rey mendigo"); y c) poemas con varias etapas redaccionales (como "Tu rostro como atónita flor escuchando la vida", "Tratando de descifrar algún instante" o "La pregunta más simple”). Para estos grupos apliqué un aparato de variantes genéticas que acoge los criterios de tipificación establecidos por el Grupo de Estudios Literarios gel de la Universidad de Antioquia —en su línea de ediciones críticas, lexicografía e interpretación de textos- Estos corresponden a la identificación de: a) tachones y reescritura por glosa interlineada; b) tachones y reescritura por glosa marginal; y c) escritura por complementación. Dos variantes fueron recurrentes en los manuscritos autógrafos:

\section{a) Tachón y reescritura por glosa interlineada}

En el poema "Otro delirio en el secreto", por ejemplo — correspondiente al grupo de los poemas "clausurados"-, Héctor Rojas Herazo procede por tachado del pasaje textual "tu asombro" y por adición con glosa interlineal de los pasajes "tu sueño" y "nombre”, sin resolución definitiva. Es decir, la imposibilidad de fijación:

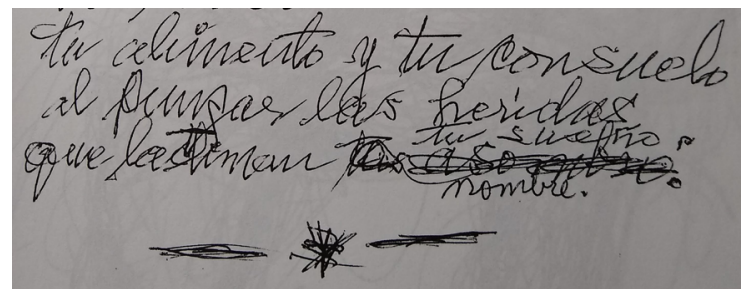

Detalle del poema "Otro delirio en el secreto" (аRв-10). Fuente: Archivo Rojas Barboza (Bogotá) y Universidad del Norte (Barranquilla). 


\section{b) Tachón y reescritura por glosa marginal}

En cuanto al poema "Bruma" — que también puede clasificarse en el grupo de poemas "clausurados"-, Héctor Rojas Herazo tacha el pasaje textual "tus propios" y adiciona con glosa marginal dos opciones de estabilización irresuelta: "brumosos" y "bruñidos".

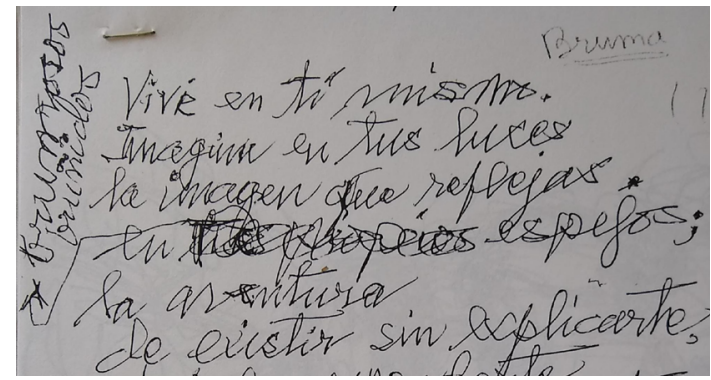

Detalle del poema "Bruma" (АRB-17a). Fuente: Archivo Rojas Barboza (Bogotá) y Universidad del Norte (Barranquilla).

Con el propósito de ordenar y explicar de manera concisa la información genética, diseñé motu proprio algunas convenciones que permitieran traducir los movimientos genéticos del autor a un código práctico y más accesible para el lector. Es así como para el caso del tachado con escritura por glosa interlineal ordené la información y explicación de la variante a pie de página del poema, donde "ARB" corresponde a las siglas del $\mathrm{A}$ (rchivo) $\mathrm{R}$ (ojas) $\mathrm{B}$ (arboza); el número 10 a la posición con que aparece numerado el manuscrito en el Archivo, y "A" a la editio princeps de Ediciones Uninorte:

ARB-IO: que lastiman turombro. [tu sueño.] [nombre.] / A: que lastiman tu nombre [La variante genética de ARB-10 tacha el pasaje "tu asombro" y ensaya dos glosas interlineales, sin resolución clara: "tu sueño" $y$ "nombre". Ta que la variante más completa corresponde a la primera, puesto que integra "tu" + "nombre", se registra como posible estadio final del poema: "lastiman tu sueño", en lugar de "lastiman nombre". La escogencia parte del iudicium del editor crítico: la supresión del pasaje "tus sueños" en el octavo verso del manuscrito obedece a un proceso revisionista muy común de la última etapa del autor, como ocurre con las sinonimias simbólicas de un poemario como Desde la luz preguntan por nosotros, "clausurado" por el autor entre 2001 y 2002, y que consiste en evitar las repeticiones léxicas].

Para los casos de tachón y reescritura por glosa marginal, ordené la información y la explicación genética de la siguiente manera — en este caso, incluyendo la comparación diacrónica con ARB-17b, que contiene la primera decodificación y transcripción a computador del manuscrito-: 
ARB-I 7 a: en tus propios [brumosos] [bruñidos] espejos / ARB -I 7 b: EN BRUMOSOS ESPEJOS / A: en brumosos espejos [La variante genética de ARB-17a tacha el pasaje "tus propios" en "tus propios espejos", que remarca la pertenencia doméstica o simbólica del objeto especular, y adiciona dos variantes genéticas que coexisten - ninguna con tachado-, salvo con una indicación de flecha, que puede ser anterior o posterior a la otra variante. Se mantiene el pasaje "brumosos" como parte de la densidad simbólica de "espejos", que supera el carácter referencial de "bruñidos", en un poema marcado por lo incierto y fugitivo].

Como puede verse, el tratamiento de pre-textualidades cuya escritura no acaba con una publicación impresa, o que, de hacerlo, son presentadas como el "resultado" último de una serie de decisiones previas - continuas, paralelas o interrumpidas, con constancia en borradores, manuscritos y mecanuscritos-, requiere abandonar la noción de texto como culminación, como telos, y concebir las pre-textualidades como capas autónomas, provisionales, que encarnan las tensiones ideológicas y estéticas de una obra in progress. Como bien sostiene Élida Lois (2005), todos aquellos que trabajan con textos genéticos, "más que señalar factores determinantes de procesos, busca[n] descubrir posibilidades, potencialidades" (p. 88). Esta característica implica que incluso las escrituras más "programadas" no resulten ser otra cosa que una de las muchas alternativas del "devenir escritural” (p. 88). En el caso de Héctor Rojas Herazo, las particularidades genéticas de Lámparas en la niebla —-más que la certeza provisional de una palabra “fijada”- pueden ayudarnos a entender las dinámicas vivas de la escritura poética del autor. O lo que es lo mismo, las múltiples transformaciones de su poética de la escritura.

\section{Referencias bibliográficas}

E1 Universal. (1948). Antología. El Universal (18 de septiembre), p. 7.

Lois, E. (2005). De la filología a la genética textual: historia de los conceptos y de las prácticas. En

F. Colla (Comp.). "Archivos”. Cómo editar la literatura latinoamericana del siglo XX (pp. 47-83). París: CRLA-Archivos.

Peña Dix, B. (2004). Estudio preliminar. En H. Rojas Herazo. Obra poética, 1938-1995 (pp. 1-30). Bogotá: Imprenta Patriótica del Instituto Caro y Cuervo.

Rojas Barbosa, P. (2021). Entrevista personal (22 de abril).

Santos García, E. (2021a). La etapa formativa (1940-1951): debates estéticos en la lírica temprana de Héctor Rojas Herazo. Estudios de literatura colombiana 49, pp. 37-52. DOI: https://doi. org/10.17533/udea.elc.n49a02

Santos García, E. (2021b). Edición critico-genética y estudio previo de la obra poética (1940-2006) de Héctor Rojas Herazo. Tesis de doctorado. Universidad de Antioquia, Facultad de Comunicaciones y Filología. 